\title{
Sintering and mechanical properties of $\mathrm{TiB}_{2}$-TiC-Ni using submicron borides and carbides
}

\author{
Zhezhen Fu, Rasit Koc* \\ Department of Mechanical Engineering and Energy Processes, Southern Illinois University, 1230 Lincoln \\ Drive, Carbondale, Illinois, US
}

\begin{abstract}
A series of $\mathrm{TiB}_{2}$-TiC-Ni composites were prepared to develop materials with enhanced mechanical properties for structural application. Submicron $\mathrm{TiB}_{2}-\mathrm{TiC}$ powders were synthesized using a patented carbon coated precursor method. The composites had about $99 \%$ relative density after sintering at a temperature of $1550^{\circ} \mathrm{C}$ in flowing argon. $\mathrm{TiB}_{2}$-TiC-Ni composites showed superior sintering and mechanical properties comparing with monolithic $\mathrm{TiB}_{2}$ and TiC counterparts because of the enhanced microstructures. Phases, grain morphologies, pores sizes, sintering behaviors, and mechanical properties were correlated with the ratio of $\mathrm{TiB}_{2} / \mathrm{TiC}$ and $\mathrm{Ni}$ content. The plate like $\mathrm{TiB}_{2}$ grains were observed in the composites. Toughening mechanism was determined as metallic binder plastics deformation, bridging, and debonding of the $\mathrm{TiB}_{2} / \mathrm{TiC}$ interface. $\mathrm{TiB}_{2}$ - $\mathrm{TiC}-\mathrm{Ni}$ composites have good combinations of hardness and fracture toughness as $24.23 \mathrm{GPa}, 7.41 \mathrm{MPa} \cdot \mathrm{m}^{1 / 2}$, and $21.85 \mathrm{GPa}, 8.44 \mathrm{MPa} \cdot \mathrm{m}^{1 / 2}$, with Ni content of 5 and $10 \mathrm{wt} \%$, respectively.
\end{abstract}

\section{Introduction}

Titanium diboride $\left(\mathrm{TiB}_{2}\right)$ has drawn enormous interest owing to its outstanding properties including high melting point $\left(3225^{\circ} \mathrm{C}\right)$, high hardness ( $\left.\sim 35 \mathrm{GPa}\right)$, excellent electrical and thermal properties, and superior wear resistance[1, 2]. By adding metallic binders such as $\mathrm{Co}, \mathrm{Fe}, \mathrm{Ni}, \mathrm{Mo}, \mathrm{Cr}$, and their alloys, $\mathrm{TiB}_{2}$ based material has improved fracture toughness due to the plastics deformation of metallic phase and crack bridging toughening $[3,4]$. Consequently, $\mathrm{TiB}_{2}$ cermet is one of the most promising candidates for cutting tool materials to substitute traditional

\footnotetext{
* Corresponding author. Email address: kocr@siu.edu
} 
WC-Co cermet, due to its superior finishing properties, hardness, and wear resistance[5-7]. Similarly, titanium carbide (TiC) based cermet, TiC-TiN-(Ni, Mo, Co), is also an ideal candidate for cutting tool materials owing to its excellent wear resistance and high hardness[8-12]. Except cutting tool materials, both $\mathrm{TiB}_{2}$ and $\mathrm{TiC}$ also have various other crucial applications from structural to electronic fields such as impact resistant armor, wear resistance components, corrosion resistance coatings, and electrode materials $[1,2,13,14]$. Comparing with monolithic $\mathrm{TiB}_{2}$ or $\mathrm{TiC}$ cermets, several reports indicate that $\mathrm{TiB}_{2}-\mathrm{Ti}(\mathrm{C}, \mathrm{N})-(\mathrm{Ni}, \mathrm{Mo})$ composite has outstanding properties including hardness, fracture toughness, and strength[5-7, 15]. However, in that respect is no research study the influence of $\mathrm{TiB}_{2} / \mathrm{TiC}$ composition (from 0 to $100 \%$ ) on the composite properties.

One of the most significant problems of $\mathrm{TiB}_{2}$ containing compound (monolithic $\mathrm{TiB}_{2}$ ceramic, $\mathrm{TiB}_{2}$ cermet, and $\mathrm{TiB}_{2}-\mathrm{TiC}$ cermet) is the sintering process[1,4]. Due to the oxygen impurity and the relatively low diffusion coefficient in commercial powders, a super high sintering temperature is required to achieve a high relative density (above 95\%). The high sintering temperature always leads to exaggerated grain grown. As a consequence, microcracks exist in sintered $\mathrm{TiB}_{2}$ due to anisotropic coefficient of thermal expansion (CTE) along a- and c-axis (grain size $>15 \mu \mathrm{m}$ ). Mechanical properties are also influenced because of coarse grain size[16]. The introducing of metallic additive can promote the sintering process through liquid phase sintering, thus reduce the sintering temperature[17, 18]. By adding above $20 \mathrm{wt} \%$ metallic binders, densifications can be accomplished at a temperature of $\sim 1500^{\circ} \mathrm{C}$ through pressureless sintering (PS)[19]. However, the high fractions of metallic phase deteriorate their wear properties, and also restrict their applications at elevated temperatures. With reduced fractions of metallic binders (5 to $10 \mathrm{wt} \%$ ), a sintering temperature up to $1700^{\circ} \mathrm{C}$ with applying external pressure simultaneously (hot pressing, HP), is necessary[5-7, 15, 20-22]. HP at the high temperature substantially reduces the production efficiency, increases costs, and restricts the product's shape. Another key issue of $\mathrm{TiB}_{2}$ based cermet for the application of structural materials is the brittleness of $\mathrm{TiB}_{2}$ itself. Several literatures indicate that fine microstructures are beneficial to the high fracture toughness $[6,7,22]$. It is necessary to study the toughening mechanism at the micro scale and tailor the microstructures, thus improve the fracture toughness.

Numerous literatures demonstrate that laboratory prepared powders have better sintering properties than that of commercially available ones[13, 23-25]. Powders with fine particle size, loose agglomeration, high purity, and regular shape are required for starting materials to enhance the sinterability $[8,13]$. By using a novel carbon 
coated precursors method, synthesized $\mathrm{TiB}_{2}, \mathrm{TiC}$, and $\mathrm{TiB}_{2}-\mathrm{TiC}$ powders can satisfy the requirements of staring powders $[8,24]$. Therefore, exceptional sintering properties are demonstrated for TiC-Ni sintering system. Although the sintering properties of $\mathrm{TiB}_{2}-\mathrm{TiC}-\mathrm{Ni}$ composites were tested, more details are needed[24].

In the present paper, by utilizing laboratory prepared $\mathrm{TiB}_{2}, \mathrm{TiB}_{2}-\mathrm{TiC}$, and $\mathrm{TiC}$ powders, by adding low fractions of $\mathrm{Ni}$ ( 5 and $10 \mathrm{wt} \%$ ), their sintering properties will be studied through PS method at a relatively low temperature. Effects of $\mathrm{TiB}_{2} / \mathrm{TiC}$ composition and $\mathrm{Ni}$ content on sintered density, phases, microstructures, and mechanical properties are observed. Correlations between microstructures and mechanical properties are discussed. A comprehensive comparison of current properties with literature reported properties are presented. The toughening mechanism of composites will also be analyzed.

\section{Experimental}

Monolithic $\mathrm{TiB}_{2}$ powders, $\mathrm{TiB}_{2}$ - $\mathrm{TiC}$ composite powders, and monolithic $\mathrm{TiC}$ powders were synthesized through a novel carbon coated precursors method[26, 27]. Powders with five different compositions, which were monolithic $\mathrm{TiB}_{2}, 80 \mathrm{wt} \% \mathrm{TiB}_{2}-20 \mathrm{wt} \% \mathrm{TiC}, 60 \mathrm{wt} \% \mathrm{TiB}_{2}-40 \mathrm{wt} \% \mathrm{TiC}, 40 \mathrm{wt} \% \mathrm{TiB}_{2}-60 \mathrm{wt} \% \mathrm{TiC}$, and monolithic TiC, were prepared. This could help study the effect of $\mathrm{TiB}_{2} / \mathrm{TiC}$ composition on sintering and mechanical properties. Powders were identified as A, B, C, D, and E, respectively. Detailed of synthesis process were described in our previous publications[24, 26]. Synthesized $\mathrm{TiB}_{2}$ powders has a particle size between 0.5 to $1 \mu \mathrm{m}$, and $\mathrm{TiC}$ is between 0.05 to $0.3 \mu \mathrm{m}$. Transmission electron microscopy (TEM, Hitachi, Model H-7650 TEM, ToKyo, Japan) micrographs of selected synthesized powders (only show $\mathrm{A}, \mathrm{C}$ and $\mathrm{E}$ to represent monolithic $\mathrm{TiB}_{2}$ powders, $\mathrm{TiB}_{2}-$ TiC composite powders, and monolithic TiC powders) are shown in Fig. 1. Owing to the advantages of carbon coated precursors method, powders features regular shape, fine particle size, high purity, and loose agglomeration[24, 28]. Synthesized powders' surface areas were characterized by BET gas adsorption surface area analyzer (Micromeritics, Gemini 2360, Nocross, GA) and summarized in Table 1.

Two batches cermets with different Ni contents were prepared. By adding $5 \mathrm{wt} \%$ Ni powders $(<1 \mu \mathrm{m}$, 99.5\% pure, CERAC, Milwaukee, WI) (total weight percent of ceramic $\mathrm{TiB}_{2}, \mathrm{TiB}_{2}$ - $\mathrm{TiC}$, or $\mathrm{TiC}$ powers were as 95 $\mathrm{wt} \%$ for each sample), powders were mixed in a plastics vial together with two plastics balls for 1 hour using a SPEX 8000 Mixer/Mill (SPEX Corp., Metuchen, NJ). The application of plastics vial and balls was aimed to 
minimize the introducing of contaminations during ball mill. Samples were recorded as A5, B5, C5, D5, and E5 respectively. Similarly, by adding $10 \mathrm{wt} \% \mathrm{Ni}$, another batch samples were also prepared and recorded as A10, B10, C10, D10, and E10. Samples with different compositions were also summarized in Table 1. Pellets were made in a single action, uniaxial press in a hardened steel die $(\mathrm{ID}=12.95 \mathrm{~mm})$ under a pressure of 200MPa. The sintering process was conducted at $1550^{\circ} \mathrm{C}$ for 1 hour in a tube furnace (CTF 17/75/300, Carbolite, Sheffield, UK) under flowing argon $(0.1 \mathrm{~L} / \mathrm{min})$. In order to study the effect of sintering temperature, $\mathrm{C} 10$ sample was also sintered at $1475^{\circ} \mathrm{C}$ for 1 hour in the tube furnace under flowing argon. Densities of sintered pellets were determined by Archimedes' method. A scanning electron microscope (SEM, FEI Quanta FEG450, Hillsboro, OR) equipped with energy Energy-dispersive X-ray spectroscopy (EDS, Oxford Instruments, United Kingdom) was used to investigate the polished surfaces using a backscattered electron detector (BSD). Sintered pellets were characterized by XRD (Rigaku D/Max-B, Tokyo, Japan) using $\mathrm{Cu} \mathrm{K \alpha}(\lambda=1.54056 \AA)$ radiation at a voltage of $30 \mathrm{KV}$ and a current of 15 mA. Phases were identified through Jade software with the International Center of Diffraction Data (ICDD). Grain size of both $\mathrm{TiB}_{2}$ and $\mathrm{TiC}$ for each sample were measured through linear interpret method performed on a Magnisci software (Divergent Rays Computing Inc, Toronto, ON, Canada). Pore sizes and volume fractions of each phase were determined through the Magnisci software as well. At least 300 grains or pores were counted from at least two images at a magnification of 1000 and one image at 2500 for each sample. Vickers hardness values were measured 10 times for each sample with a Shimazdu HSV-20 hardness tester at a load of $20 \mathrm{~kg}$. The fracture toughness was determined using the Vickers hardness indentation method[29]:

$$
K_{I C}=\delta\left(\frac{E}{H_{V}}\right)^{1 / 2} P C_{0}^{-\frac{3}{2}}
$$

where: $\mathrm{K}_{\mathrm{IC}}$ is the fracture toughness, $\delta$ is a constant value of $0.016 \pm 0.004$, E is the Young's modulus (taken from literature data and the law of mixture was applied for composites)[1,2], $\mathrm{H}_{\mathrm{V}}$ is the Vickers hardness, $\mathrm{P}$ is the indentation load, and $\mathrm{C}_{0}$ is the crack length measured from the center of the indent. It should be clarified that, the most widely used Shetty equation for cermet carbide's toughness determination, was not applied to current calculation due to the formation of median cracking $[3,30]$. 



(b)



\section{$1 \mu \mathrm{m}$}

Fig. 1 TEM micrographs of synthesized powders. (a) monolithic $\mathrm{TiB}_{2}$ powders, identified as $\mathrm{A}$, (b) composite powders, $60 \mathrm{wt} \% \mathrm{TiB}_{2}-40 \mathrm{wt} \% \mathrm{TiC}$, identified as $\mathrm{C}$, (c) monolithic TiC powders, identified as $\mathrm{E}$. Notice the different magnifications to show detailed morphology of synthesized powders. 
Table 1 A summary of synthesized powders and sintered samples

\begin{tabular}{|c|c|c|c|c|c|}
\hline $\begin{array}{c}\text { Composition of } \\
\text { synthesized powders }\end{array}$ & Powders ID & $\begin{array}{c}\text { Surface area, } \\
\mathrm{m}^{2} / \mathrm{g}\end{array}$ & $\begin{array}{l}\text { Powders } \\
\text { impurities }\end{array}$ & Adding $5 \% \mathrm{Ni}$ & Adding $10 \% \mathrm{Ni}$ \\
\hline $\mathrm{TiB}_{2}$ & $\mathrm{~A}$ & 2.4 & & A5 & A10 \\
\hline $80 \% \mathrm{TiB}_{2}-20 \% \mathrm{TiC}^{*}$ & B & 4.7 & Trace amount of & B5 & $\mathrm{B} 10$ \\
\hline $60 \% \mathrm{TiB}_{2}-40 \% \mathrm{TiC}$ & $\mathrm{C}$ & 5.8 & free carbon and & $\mathrm{C} 5$ & $\mathrm{C} 10$ \\
\hline $40 \% \mathrm{TiB}_{2}-60 \% \mathrm{TiC}$ & $\mathrm{D}$ & 7.2 & oxygen & D5 & D10 \\
\hline $\mathrm{TiC}$ & E & 11.3 & & E5 & E10 \\
\hline
\end{tabular}

*All percentages are weight percent

\section{Results and discussion}

3.1 Relative density

Fig. 2 illustrates the relative density after sintered at $1550^{\circ} \mathrm{C}$ for 1 hour with the function of $\mathrm{TiB}_{2}-\mathrm{TiC}$ and $\mathrm{Ni}$ content. All samples reach above $94 \%$ relative density even with $5 \mathrm{wt} \% \mathrm{Ni}$ additive. A5 sample has a relative density of $94 \%$. By introducing TiC phase, the relative density increases to $94.5 \%$ for B5. With the increasing of TiC content, C5 and D5 have the highest relative density of $99.3 \%$ and $98.8 \%$, respectively. For the sample of TiC$5 \mathrm{Ni}$, the relative density is $96.2 \%$. A similar relative density as a function of $\mathrm{TiB}_{2}-\mathrm{TiC}$ composition can be observed by adding $10 \mathrm{wt} \% \mathrm{Ni}$. The relative density of $\mathrm{C} 10$ and $\mathrm{D} 10 \mathrm{is} \sim 99 \%$. As a comparison, the relative density of $\mathrm{TiB}_{2}-$ $10 \mathrm{Ni}$ and $\mathrm{TiC}-10 \mathrm{Ni}$ (A10 and E10) is $95.9 \%$ and $97.8 \%$, respectively. It also should be mentioned that most samples contain $10 \mathrm{wt} \% \mathrm{Ni}$ show slightly higher relative density for the ones with $5 \% \mathrm{Ni}(\mathrm{A}, \mathrm{B}, \mathrm{D}$, and E). Overall, the composites with proper $\mathrm{TiB}_{2} / \mathrm{TiC}$ ratio (C and D composite powders, $\mathrm{C} 5, \mathrm{D} 5, \mathrm{C} 10, \mathrm{D} 10$ composites) show the best sintering properties with relative density of $\sim 99 \%$.

Literatures report the sintering temperature of TiC-Ni cermet is normally in the range of 1400 to $1550^{\circ} \mathrm{C}$, which is similar to the current research $[8-10,12]$. However, for $\mathrm{TiB}_{2}$ containing cermet, hot pressing is necessary to produce dense sample ( $>94 \%$ relative density). Agaogullari et al report that $\mathrm{TiB}_{2}-\mathrm{Co}$ and $\mathrm{TiC}-\mathrm{TiB}_{2}-\mathrm{Ni}-\mathrm{X}$ pressureless sintered at $\sim 1550^{\circ} \mathrm{C}$ only reach $\sim 69$ to $85 \%$ relative density[19, 31]. Zou et al claim dense TiC-TiB $2-\mathrm{Ni}$ 
can be prepared at $1650^{\circ} \mathrm{C}$ through hot pressing $[5,7,15,22]$. Obviously, the synthesized powders show excellent sintering properties. The synthesized fine powders can greatly increase the capillary fore and decrease the mass transport distance during liquid phase sintering[8]. It also should be noted that the high levels of free carbon and oxygen in commercially available powders leads to the alteration of surface free energy, and inhibit the diffusion and densification. The low contaminations of synthesized powders ensure the densification occurs at a relative low temperature. Details regarding the sintering behavior will be discussed later with the appearance of microstructures.

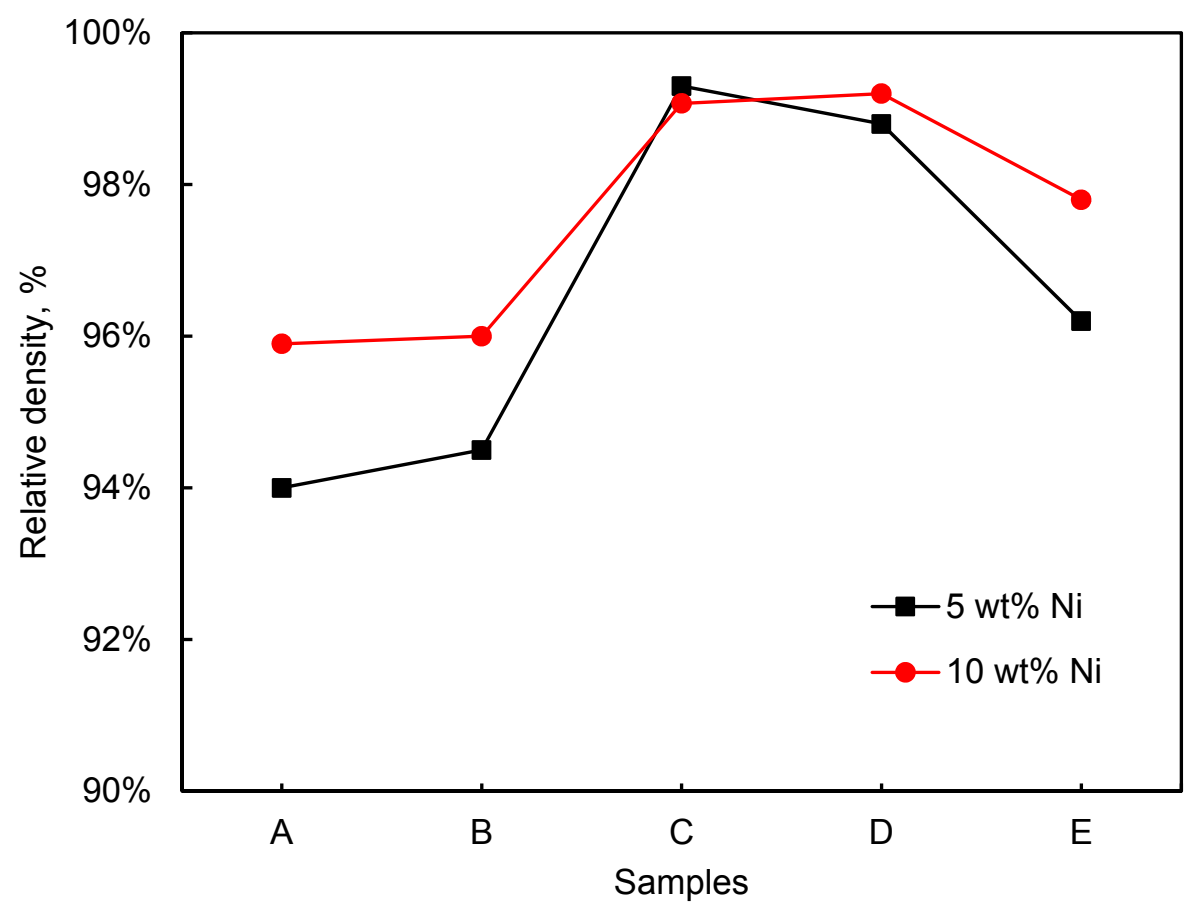

Fig. 2 Relative density of samples sintered at $1550^{\circ} \mathrm{C}$ for 1 hour in argon atmosphere

\subsection{Phases composition}

Fig. 3 shows the XRD patterns of selected sintered samples. Samples contain $10 \mathrm{wt} \% \mathrm{Ni}, \mathrm{A} 10, \mathrm{C} 10$, and E10, were selected in order to observe the Ni compounds. It should be clarified that the peak position of Ni (111) $\left(44.507^{\circ}\right)$ is close to $\mathrm{TiB}_{2}(101)\left(44.437^{\circ}\right)$, therefore $\mathrm{Ni}(111)$ peak cannot be observed for A10 and $\mathrm{C} 10$. From Fig. 3, except $\mathrm{TiB}_{2}$, TiC, and $\mathrm{Ni}$, no other phases can be observed. This indicates that no serious chemical reaction occurs during sintering process. Previous literatures claim that $\mathrm{Ni}_{\mathrm{x}} \mathrm{Ti}_{\mathrm{y}}, \mathrm{Ni}_{\mathrm{x}} \mathrm{B}_{\mathrm{y}}$ (it is hypothesized as $\mathrm{Ni}_{3} \mathrm{~B}$ based on previous report $[4,17])$, and $\mathrm{Ti}_{2} \mathrm{O}_{3}$ form after sintered because of the reactions between $\mathrm{Ni}, \mathrm{TiC}, \mathrm{TiB}_{2}$, and other impurities. 
However, these three phases cannot be identified from XRD patterns. There are two reasons to address this problem: (1) low free Ti and oxygen contaminations in the starting powders benefitting from the synthesis process [8, 24, 28];

(2) $\mathrm{Ni}_{\mathrm{x}} \mathrm{B}_{\mathrm{y}}$ can be observed through EDS (as shown in Fig. 8a, will discuss later), however the content of $\mathrm{Ni}_{\mathrm{x}} \mathrm{B}_{\mathrm{y}}$ is relatively low and has exceeded the detecting limitation of XRD.

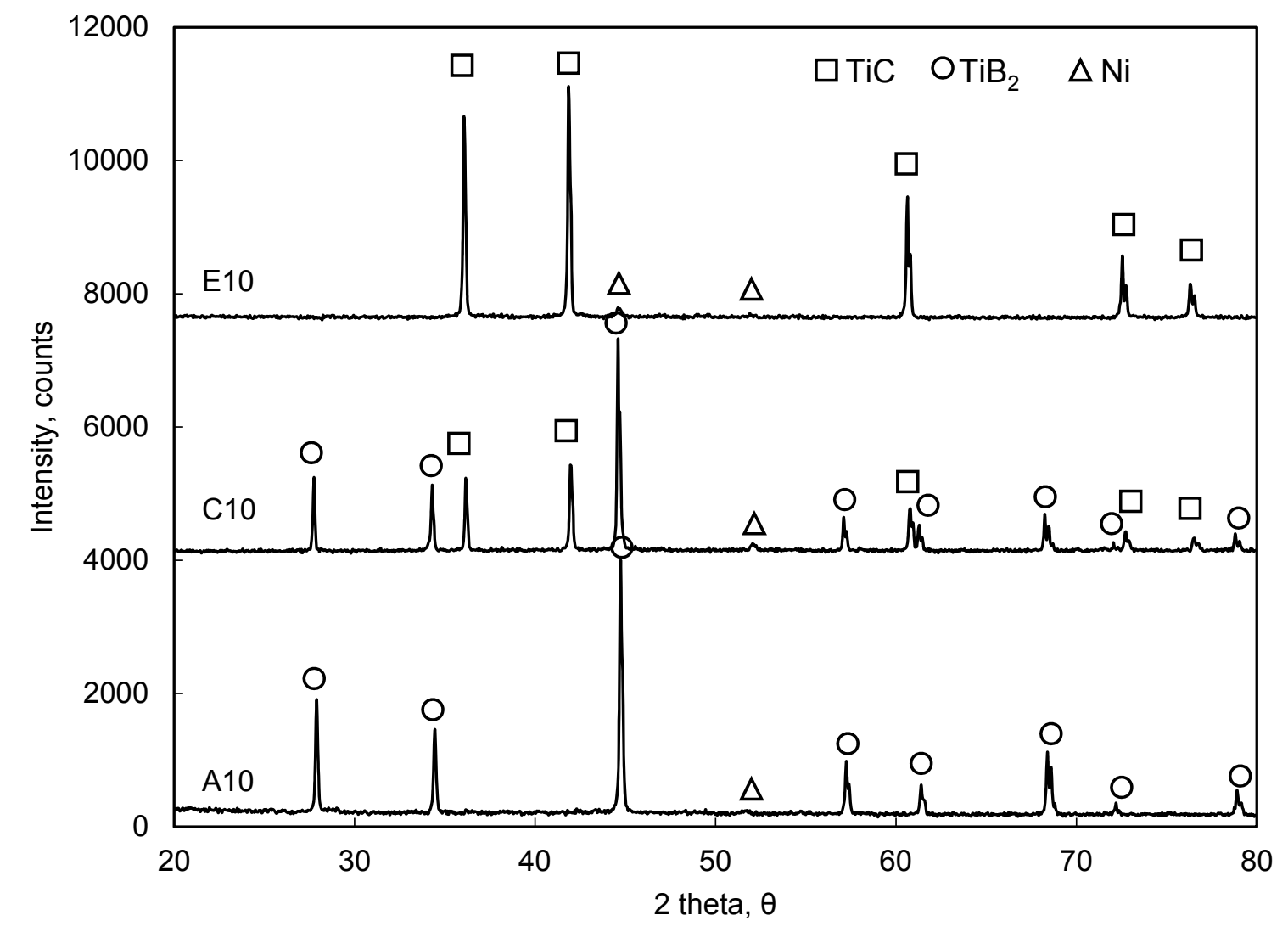

Fig. 3 XRD patterns of selected sintered samples with content of 10 wt.\% Ni: A10, C10, and E10.

\subsection{Microstructures}

BSD microstructures of sintered samples containing 5 and $10 \mathrm{wt} \% \mathrm{Ni}$ are shown in Fig. 4 and Fig. 5 , respectively. It is known that low atomic weight phases have darker imaging through BSD. Dark, charcoal grey, grey, and white phases are identified as pores, $\mathrm{TiB}_{2}, \mathrm{TiC}$, and $\mathrm{Ni}$ respectively, which are also confirmed by element detection through EDS. As mentioned before, $\mathrm{Ni}_{\mathrm{x}} \mathrm{B}_{\mathrm{y}}$ phase can be observed through EDS. However, due to the limitation of boron detection through EDS, it is not clear what exact nickel boride phase exist in the system. Volume 
fractions obtained from the Magnsci software of pores, $\mathrm{TiB}_{2}, \mathrm{TiC}$, and $\mathrm{Ni}$ are also in good agreement with the relative density and starting compositions (need convert weight percentages to volume fractions).

The grain size of $\mathrm{TiB}_{2}$ and $\mathrm{TiC}$ is summarized in Table 2. A high solid fraction can accelerate the rate of grain growth because of decreased diffusion distance[32]. Therefore, sample with $10 \mathrm{wt} \% \mathrm{Ni}$ have finer grain size correspondingly. $\mathrm{TiB}_{2}-\mathrm{Ni}$ samples have the largest grain size for $\mathrm{A} 5$ and $\mathrm{A} 10$. With the introducing of $20 \mathrm{wt} \% \mathrm{TiC}$ as the secondary solid phase (B samples), grain growth of $\mathrm{TiB}_{2}$ is inhibited, which also indicates that the grain shape accommodation is obstructed. So, instead of regular shape, polygon $\mathrm{TiB}_{2}$ grains can be found. With the increasing content of $\mathrm{TiC}$ phase, the grain size of $\mathrm{TiB}_{2}$ continues reducing while $\mathrm{TiC}$ increasing. The exaggerated $\mathrm{TiC}$ grain growth exists in $\mathrm{C}$, while $\mathrm{C} 10$ sample has a fine grain size owing to the high Ni content. For both $\mathrm{C}$ and D samples, $\mathrm{TiB}_{2}$ mainly have polygon and plate like grains while polygon grains for $\mathrm{TiC}$. When monolithic $\mathrm{TiC}$ as the ceramic matrix, apparent exaggerated grain growth can be found in both E samples, as shown in Fig. 4e and Fig. 5e.

Porosity levels as can be observed in Fig. 4 and Fig. 5 are consistent with the relative density shown in Fig. 2. A, B and E samples have relative high porosity level comparing with $\mathrm{C}$ and $\mathrm{D}$. A few pores can be observed for $\mathrm{C}$ and D samples (Fig. 4c, d and Fig. 5c, d), which confirms the high relative density ( $\sim 99 \%$ ). The average pore size in $\mu \mathrm{m}$ measured from Magnsci is shown in Fig. 6. Large round pores can clearly be observed for A samples (Fig. 4a and Fig. 5a) locate in $\mathrm{TiB}_{2} / \mathrm{TiB}_{2}$ interfaces or close to the triple point. There are also a few fine pores located within some exaggerated grown $\mathrm{TiB}_{2}$ grains. With the introducing of a small amount of $\mathrm{TiC}$, large pores as can be observed in B samples are similar to A samples, but with some fine pores at $\mathrm{TiB}_{2} / \mathrm{TiC}$ interfaces (Fig. $4 \mathrm{~b}$ and Fig. 5b). With the $\mathrm{TiC}$ content increasing, only fine pores can be observed and are mainly located at $\mathrm{TiB}_{2} / \mathrm{TiC}$ grain boundaries (Fig. 4c and Fig. 5c). There are no obvious pores within grains due to the inhibited grain growth. A BSD micrograph at higher magnification of $\mathrm{C} 10$ clearly shows the fine pores at grain boundaries between $\mathrm{TiB}_{2}$ and $\mathrm{TiC}$ (Fig. 8). The pores of D5, E5, and E10 are primarily locating within exaggerated grown $\mathrm{TiC}$ grain, along with some fine pores near interfaces. D10 has a fine pore sizes comparing with D5, which is because that the high liquid content slows the TiC grain growth, and consequently mainly fine pores. 

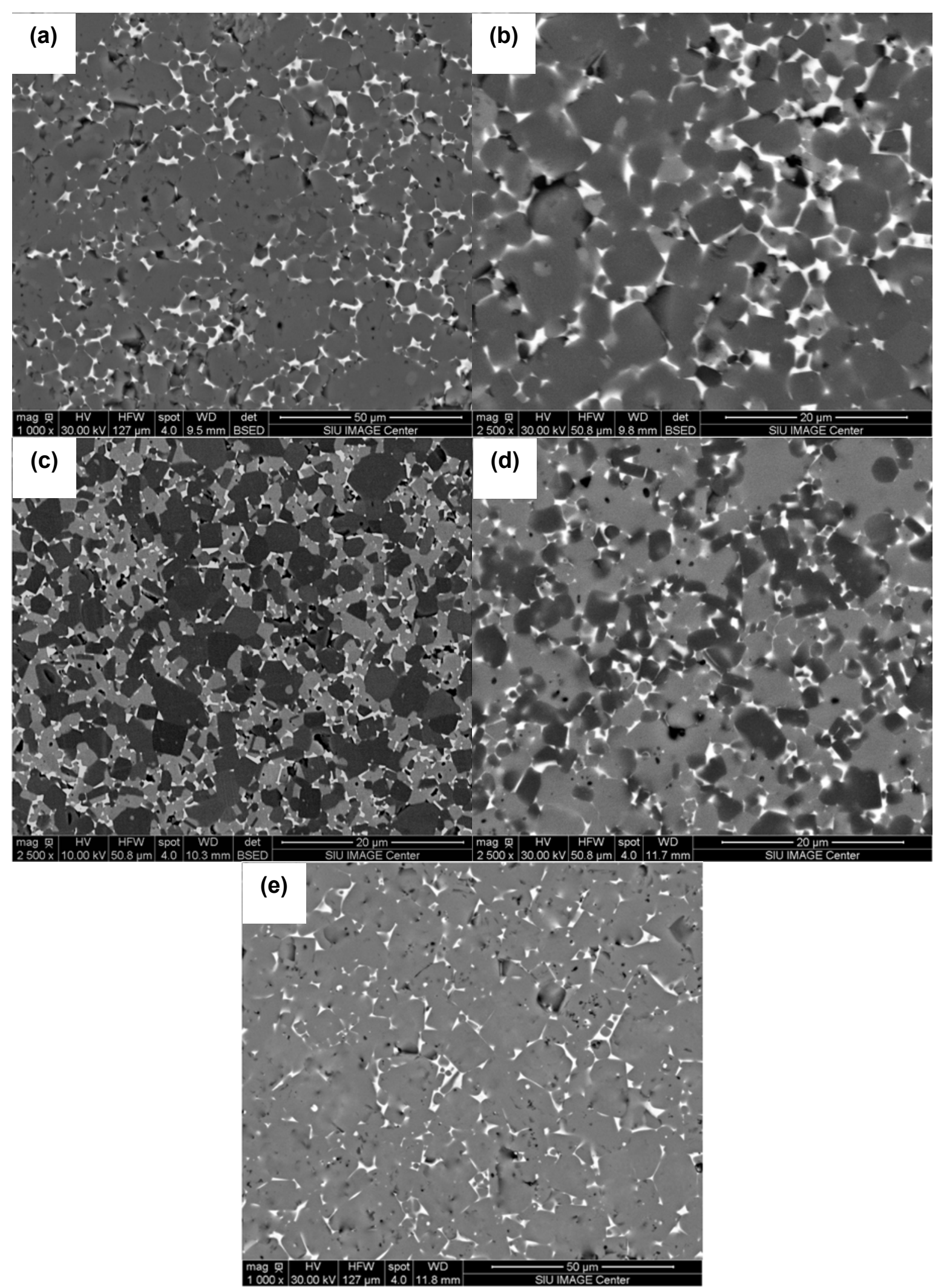

Fig. 4 BSD micrographs of sintered samples containing 5 wt.\%Ni. (a) A5, (b) B5, (c) C5, (d) D5, (e) E5. 

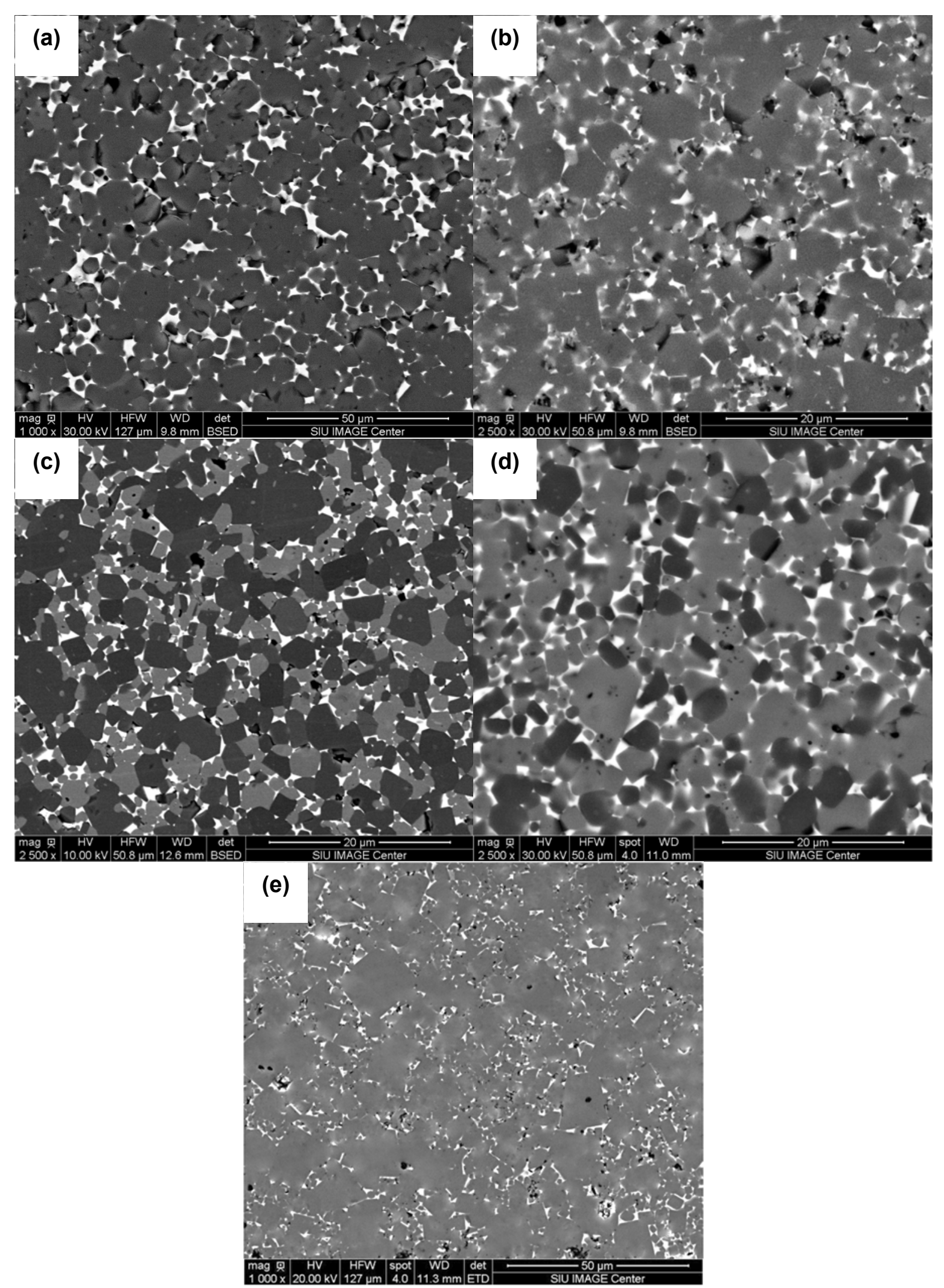

Fig. 5 BSD micrographs of sintered samples containing 10 wt.\%Ni. (a) A10, (b) B10, (c) C10, (d) D10, (e)

E10. 


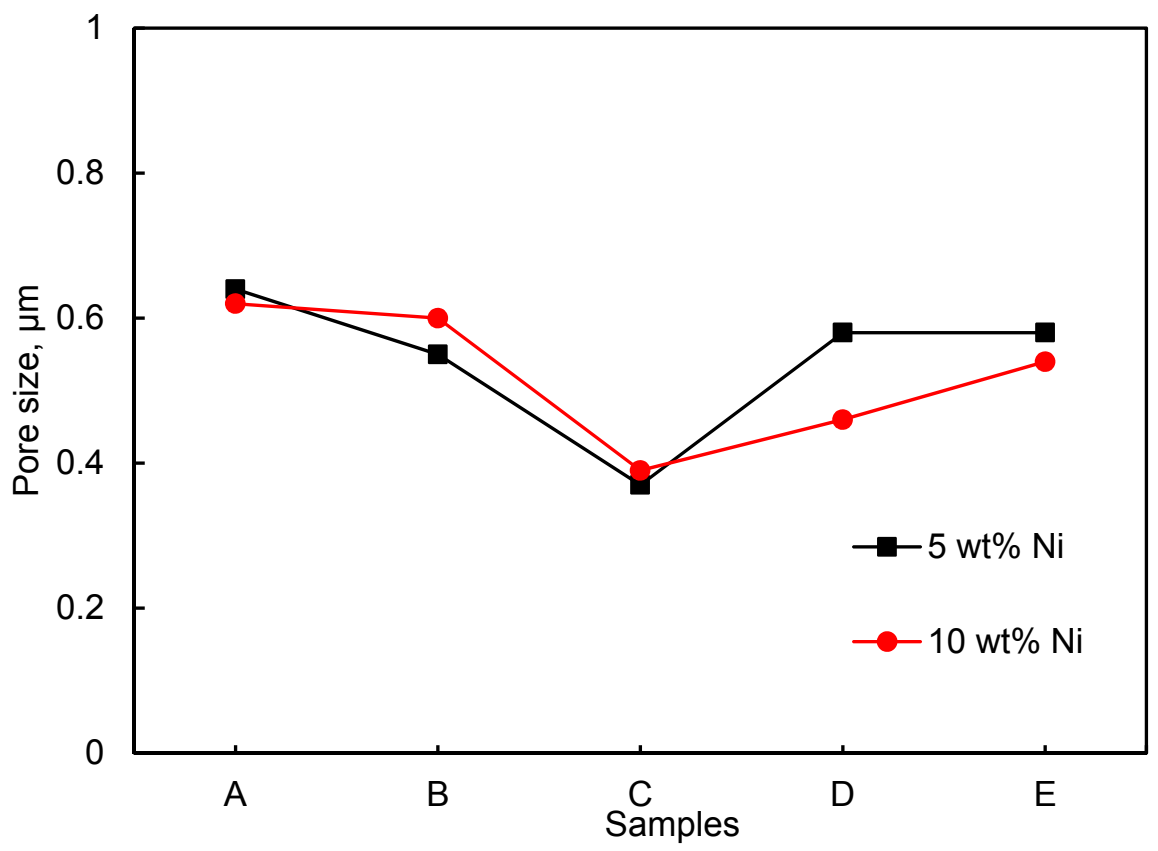

Fig. 6 Pore size in $\mu \mathrm{m}$ of samples sintered at $1550^{\circ} \mathrm{C}$ for 1 hour

Table 2 Grain size of $\mathrm{TiB}_{2}$ and $\mathrm{TiC}$ for sintered samples

\begin{tabular}{cccc}
\hline & Samples & $\mathrm{TiB}_{2}$ grain size, $\mu \mathrm{m}$ & TiC grain size, $\mu \mathrm{m}$ \\
\hline & $\mathrm{A} 5$ & 12.5 & $\mathrm{~N} / \mathrm{A}$ \\
By adding 5 & $\mathrm{B} 5$ & 3.5 & 1.2 \\
wt. \%Ni & $\mathrm{C} 5$ & 2.2 & 1.5 \\
& $\mathrm{D} 5$ & 1.4 & 2.8 \\
& $\mathrm{E} 5$ & $\mathrm{~N} / \mathrm{A}$ & 7.2 \\
\hline & $\mathrm{A} 10$ & 9.2 & $\mathrm{~N} / \mathrm{A}$ \\
By adding 10 & $\mathrm{B} 10$ & 2.6 & 1.1 \\
wt. \%Ni & $\mathrm{C} 10$ & 2 & 1.5 \\
& $\mathrm{D} 10$ & 1.4 & 2.5 \\
& $\mathrm{E} 10$ & $\mathrm{~N} / \mathrm{A}$ & 5.2 \\
\hline
\end{tabular}

\subsection{Sintering behavior}

The principal driving force for liquid phase sintering is the capillarity and surface tension[33]. Fine particle size and low contact angle are beneficial to the densification because of the high capillarity and surface tension[8]. As can be observed in Fig. 1, the particle size of $\mathrm{TiB}_{2}$ and $\mathrm{TiC}$ is submicron grade $(0.5$ to $1 \mu \mathrm{m})$ and nano grade $(0.05$ 
to $0.3 \mu \mathrm{m}$ ), respectively. The contact angle between $\mathrm{TiC} / \mathrm{Ni}$ and $\mathrm{TiB}_{2} / \mathrm{Ni}$ is $\sim 23^{\circ}$ and $\sim 40^{\circ}$ respectively from previous literatures[34]. It is noteworthy that the contact angle is varying with atmosphere, temperature, and impurity. However, it is clear that the wetting ability between $\mathrm{TiC}$ and $\mathrm{Ni}$ is better than that of $\mathrm{TiB}_{2} / \mathrm{Ni}$.

As the main coarsening mechanism, coalescence influences both grain size and pore size[33]. Coalescence, which is also named as Ostwald ripening, occurs due to the grain boundary curvature, and follows the solutionreprecipitation procedure as indicated in Fig. 7a: (1) dissolution of fine $\mathrm{TiC} / \mathrm{TiB}_{2}$ grains with high positive curvature; (2) diffusion toward coarse $\mathrm{TiC} / \mathrm{TiB}_{2}$ grains through liquid phase; (3) precipitation of dissolved fine on coarse $\mathrm{TiC} / \mathrm{TiB}_{2}$ grains. Coalescence of grains leads to the grain growth and shape accommodation, which is demonstrated by the regular $\mathrm{TiB}_{2}$ grain shape (Fig. 3a, Fig. 4a). It should be acknowledged that the appearance of polygon TiC grains is dictated by the anisotropic surface energy of different crystallographic orientations[35, 36].

Differences in particle size and contact angel can explain that E samples (TiC-Ni, low contact angel, nano particle size) have higher relative density than $\mathrm{A}$ samples ( $\mathrm{TiB}_{2}-\mathrm{Ni}$, high contact angel, submicron particle size). Pore filling is favorable for low contact angle systems during the intermediate stage of liquid phase sintering. However, for $\mathrm{TiB}_{2}-\mathrm{Ni}$ samples, because of the high contact angle, large round pores may accumulate at the interfaces and triple points which are not able to be filled (Fig. 4a, 5a). Pore growth, similar to the grain growth through Ostwald ripening, is because of different solubility of large and small pores in the matrix. As a consequence, the large pores grow with the expense of small pores. The pores growth is not controllable because of the coalescence. Consequently, large pores form and lead to the low sintered density. The pores can either locate near grain boundaries or within exaggerated grown grains. Large round pores influence the relative density of $\mathrm{TiB}_{2}-\mathrm{Ni}$ cermet (94\% and 95.9\% respectively for A5 and A10). These large pores are not able to be eliminated except applying external pressure (HP)[3, 4]. Wetting ability between $\mathrm{TiC}$ and $\mathrm{Ni}$ is better, thus the higher relative density comparing with $\mathrm{TiB}_{2}-\mathrm{Ni}(96.2 \%, 97.8 \%$ respectively for E5 and E10). Trapped gas pores also form because of the solubility between the sintering atmosphere and $\mathrm{TiC} / \mathrm{TiB}_{2} / \mathrm{Ni}$ with the process of coalescence. It is known that the oxygen impurities in $\mathrm{TiB}_{2}$ are mainly in the form of $\mathrm{B}_{2} \mathrm{O}_{3}$ and $\mathrm{Ti}_{\mathrm{x}} \mathrm{O}_{\mathrm{y}}$. $\mathrm{Ni}_{\mathrm{x}} \mathrm{B}_{\mathrm{y}}$ forms via the reaction between $\mathrm{Ni}$ and $\mathrm{TiB}_{2}$ as mentioned before. Both $\mathrm{B}_{2} \mathrm{O}_{3}$ and $\mathrm{Ni}_{\mathrm{x}} \mathrm{B}_{\mathrm{y}}$ have relative high vapor pressures at the temperature range of $\sim 1550^{\circ} \mathrm{C}[17,25,37]$. Therefore, the atmosphere during the sintering process for $\mathrm{TiB}_{2}$ containing samples includes argon and volatiles from $\mathrm{B}_{2} \mathrm{O}_{3}$ and $\mathrm{Ni}_{\mathrm{x}} \mathrm{B}_{\mathrm{y}}$. As a comparison, trapped gas pores in TiC-Ni cermet are mainly due to 
the argon atmosphere. Trapped gas pores (argon and volatiles) in sintered $\mathrm{TiB}_{2}-\mathrm{Ni}$ also contribute to the high porosity level than that of $\mathrm{TiC}-\mathrm{Ni}$ cermets (mainly argon). $\mathrm{TiB}_{2}-\mathrm{Ni}$ and $\mathrm{TiC}-\mathrm{Ni}$ cermets have large pore size and it is not able to reach higher density in current sintering condition.

Coalescence is inhibited for $\mathrm{TiB}_{2}$-TiC-Ni composites, as illustrated in Fig. 7 b. Set the coalescence of $\mathrm{TiB}_{2}$ grains as an example, with the appearance of secondary $\mathrm{TiC}$ phase, fine $\mathrm{TiB}_{2}$ grains can only dissolved into liquid phase without further diffusion toward coarse grains. The coalescence of $\mathrm{TiB}_{2}$ is prevented during the second step of solution-reprecipitation. For TiC, however, considering the nano particle size, coalescence of $\mathrm{TiC}$ may occur in certain conditions, as illustrated in Fig. $7 \mathrm{~b}$ of grey grains. When the TiC grain reaches a certain size, additional coalescence is restrained. The coalescence not only contributes coarse but also densification. Theoretically, the lack of coalescence will lead to a low relative density. Some pores are not able to be filled by the liquid penetration as shown in Fig. 7b, especially when liquid fraction is relatively low (5 and $10 \mathrm{wt} \%$ ). As shown in Fig. 8b, with a sintering temperature of $1475^{\circ} \mathrm{C}$, a significant amount of remaining pores can be observed, especially at the grain boundaries of $\mathrm{TiC}$ and $\mathrm{TiB}_{2}$. It is necessary to increase the sintering temperature $\left(1550^{\circ} \mathrm{C}\right.$ for current paper) and eliminate the remaining pores through solid state sintering. $\mathrm{TiB}_{2}$ grain shape accommodation is also inhibited. Instead of regular grains, polygon and plate like $\mathrm{TiB}_{2}$ grains can be observed in $\mathrm{TiB}_{2}$ - $\mathrm{TiC}-\mathrm{Ni}$ composites as mentioned before. Polygon grains are relative large comparing with those plate like grains as shown in Fig. 8a. As reported in previous literatures[1,16,38], $\mathrm{TiB}_{2}$ has a hexagonal close packed structure $(\mathrm{C} 32, \mathrm{a}=3.033$ and $\mathrm{c}=$ 3.23), with the stacking of Ti planes and B network along the c-direction. The fastest growing planes of $\mathrm{TiB}_{2}$ are the

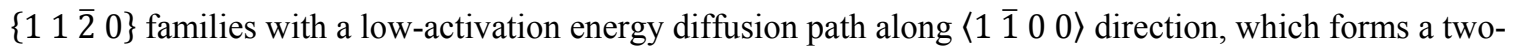
dimensional network. Hence $\mathrm{TiB}_{2}$ tends to grow into a plate like morphology initially (Fig. 8a red circles), with the c-axis perpendicular to the plate plane. With the continue growing of $\mathrm{TiB}_{2}$ grains, plate like grains accommodate to polygon grains. This explains the appearance of fine $\mathrm{TiB}_{2}$ plate like grains and relatively large polygon grains. Another advantage of the introducing of $\mathrm{TiC}$ phase is that fine $\mathrm{TiC}$ particles/grains can fill some large pores at the interface of $\mathrm{TiB}_{2} / \mathrm{TiB}_{2}$, due to the good solubility of $\mathrm{TiC}$ in liquid Ni. Fine pores form as discussed before. Part of these fine pores can be eliminated through solid state sintering as mentioned. In short, the introducing of TiC phase is beneficial to high relative density. However, it is interesting that all B samples have similar relative density with A samples correspondingly. Although a sufficient high sintering temperature is supplied, the volatiles from impurities in $\mathrm{TiB}_{2}$ and poor wetting ability of $\mathrm{TiB}_{2} / \mathrm{Ni}$ still lead to the formation of large pores. With the decreasing 
of $\mathrm{TiB}_{2}$ content, volatiles have been minimized, consequently have the highest relative density ( $\mathrm{C}$ and $\mathrm{D}$ samples). With the occurrence of exaggerated grown of TiC grains (D5, E5, E10, especially E samples), large entrapped gas pores form and result in the reduction of relative density.

a
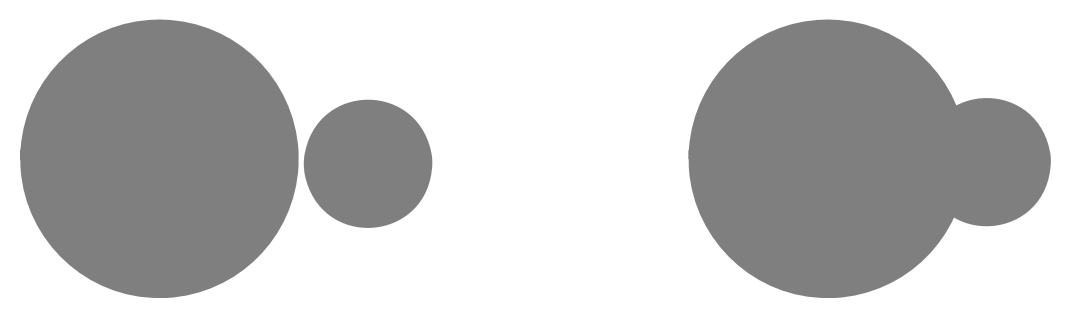

b
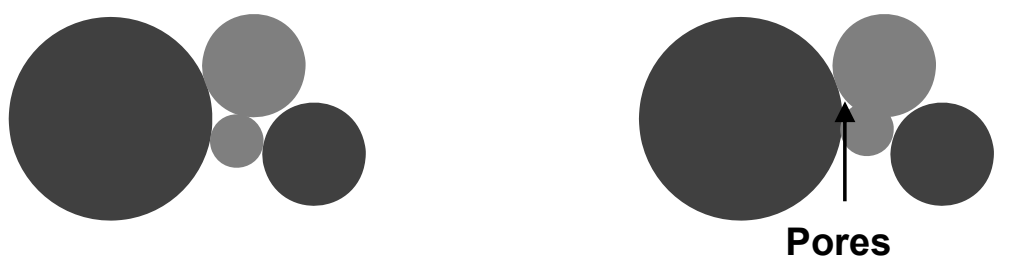

Fig. 7 Coalescence process of monolithic and composite. (a) coalescence of monolithic; (b) coalescence of composite, dark grey ones represent $\mathrm{TiB}_{2}$ grains and grey ones represent $\mathrm{TiC}$ grains 


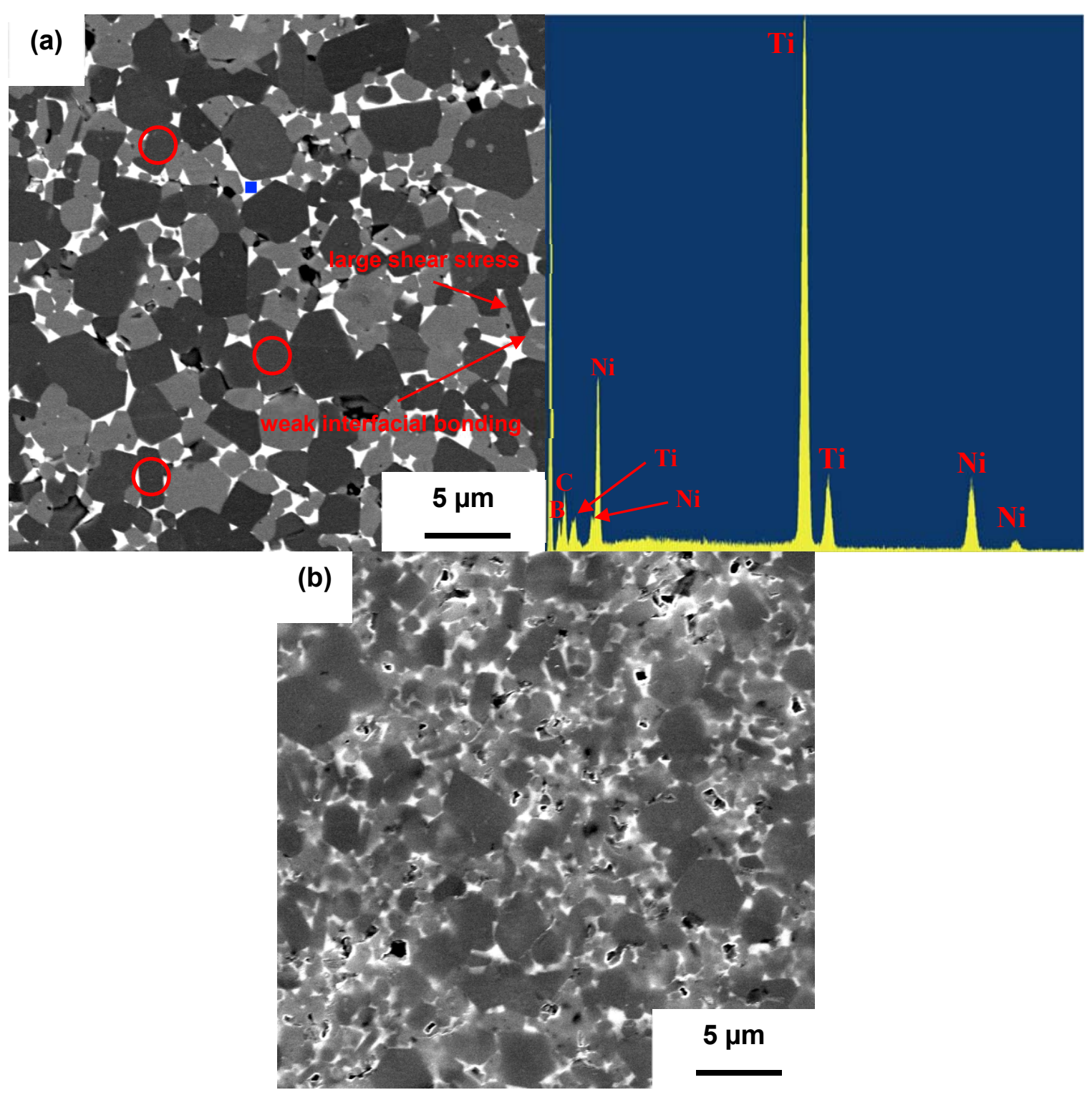

Fig. 8 High magnification BSD micrographs of C10 sample at different sintering temperatures for one hour. (a) C10 sample sintered at $1550^{\circ} \mathrm{C}$ along with EDS spectrums of the binder phase (selected blue point), (b) $\mathrm{C} 10$ sample sintered at $1475^{\circ} \mathrm{C}$

\subsection{Hardness}

Fig. 9 shows the Vickers hardness of sintered samples over $\mathrm{TiB}_{2} / \mathrm{TiC}$ compositions and $\mathrm{Ni}$ contents. The Vickers hardness for A5 and A10 is 19.94 and $17.62 \mathrm{GPa}$, respectively. With the introducing of TiC, the hardness 
slightly decreases to 19.36 and 17.35 GPa for B5 and B10 samples. C samples have the highest hardness, which is 24.23 and $21.85 \mathrm{GPa}$ with 5 and $10 \mathrm{wt} \% \mathrm{Ni}$. Hardness decreases with more TiC for D and E samples.

Hardness is greatly dependent on relative density. It is obvious that samples with high relative density (C and D samples) have high hardness. Except relative density, hardness is also influenced by Ni content, the hardness of ceramic matrix (can be influenced by $\mathrm{TiB}_{2} / \mathrm{TiC}$ composition because $\mathrm{TiB}_{2}$ and $\mathrm{TiC}$ have different hardness, $\mathrm{TiB}_{2}$ : 25-35GPa, TiC: 24-32GPa[1, 2]), and microstructures[39]:

$$
\mathrm{H}=\mathrm{a} H_{S} \times C_{S S}+b H_{S} \times V_{S}+H_{L} \times V_{L}\left(1-G^{-\frac{1}{2}}\right)
$$

Where $\mathrm{H}$ is the hardness, $\mathrm{a}$ and $\mathrm{b}$ are constants, $\mathrm{H}_{\mathrm{S}}$ is the hardness of the ceramic matrix, $\mathrm{V}_{\mathrm{S}}$ is the volume fraction of ceramic, $\mathrm{H}_{\mathrm{L}}$ is the hardness of $\mathrm{Ni}, \mathrm{V}_{\mathrm{L}}$ is the volume fraction of $\mathrm{Ni}, \mathrm{C}_{\mathrm{SS}}$ is the contiguity, and $\mathrm{G}$ is the grain size. $\mathrm{C}_{\mathrm{SS}}$ can be measured using the number of intercepts per unit length of test line $\mathrm{N}[32]$ :

$$
C_{S S}=\frac{2 N_{S S}}{2 N_{S S}+N_{S L}}
$$

Where $N_{s s}$ and $N_{S L}$ is the ceramic-ceramic and ceramic-Ni intercepts per unit length N. From above equation, obviously, samples contain $5 \mathrm{wt} \% \mathrm{Ni}$ have higher hardness than with $10 \mathrm{wt} \% \mathrm{Ni}$ for each $\mathrm{TiB}_{2} / \mathrm{TiC}$ composition. Another factor need consider is that the hardness of $\mathrm{TiB}_{2}(25-35 \mathrm{GPa})$ is somewhat higher than $\mathrm{TiC}$ (24-32GPa). B samples have similar relative density comparing with A samples but a slightly lower hardness. Although the fine grain size of B samples contributes to a high hardness, the presence of TiC decreases the hardness. Except high relative density, fine grain size in $\mathrm{C}$ and $\mathrm{D}$ samples $(\sim 1.4-2.8 \mu \mathrm{m})$ also results in the high hardness. It is worth mentioning that the difference between the hardness of $\mathrm{C}$ and $\mathrm{D}$ samples is much more notable comparing with $\mathrm{A}$ and $\mathrm{B}$ samples. The most obvious reason is that $\mathrm{C}$ samples have higher $\mathrm{TiB}_{2}$ content than that of $\mathrm{D}$ samples, as discussed before. Another reason should be attributed to the different volume fractions of ceramic phase. The density of $\mathrm{TiB}_{2}\left(4.52 \mathrm{~g} / \mathrm{cm}^{3}\right)$ is slightly lower than $\mathrm{TiC}\left(4.93 \mathrm{~g} / \mathrm{cm}^{3}\right)$, as a consequence, the volume fraction of ceramic phase in C is higher than D (for instance, $97.31 \mathrm{vol} \%$ for $\mathrm{C} 5$ and $97.26 \mathrm{vol} \%$ for D5). The high volume fraction of ceramic phase causes the high hardness, as indicated in above equation. The relative high ceramic phase volume fraction in $\mathrm{C}$ sample also results in a high contiguity. The high contiguity aids the hardness because of greater rigidity from the ceramic-ceramic contracts. The measured contiguity of C5 and D5 is 0.78 and 0.71 , respectively. The high volume fraction of ceramic phase and contiguity in $\mathrm{C}$ samples give another reason of the notable higher hardness of C sample comparing with D sample. The hardness of present paper is remarkably higher than previously 
reported $\mathrm{TiC}_{-} \mathrm{TiB}_{2}-\mathrm{Ni}$ composite with similar binder content. The hardness from literatures is in the range of 20.22 to $22.54 \mathrm{GPa}$ with binder content of 5 to $10 \mathrm{wt} \%[5,6,15,40]$. This is also ascribed to the high relative density and fine grain size as discussed.

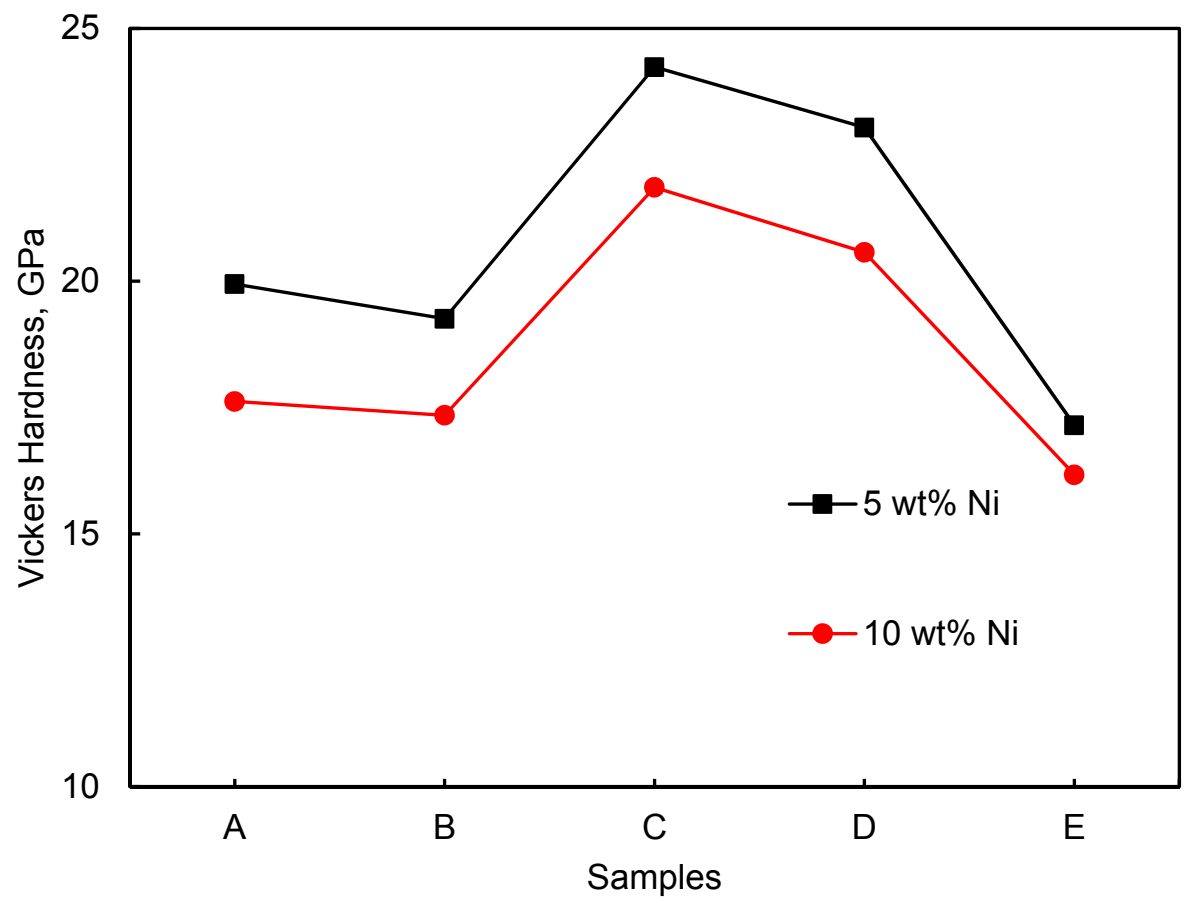

Fig. 9 Vickers hardness of samples sintered at $1550^{\circ} \mathrm{C}$ for one hour over $\mathrm{TiB}_{2} / \mathrm{TiC}$ composition and $\mathrm{Ni}$ content

\subsection{Fracture toughness}

Fracture toughness obtained from Vickers indentation technique is shown in Fig. 10. Fracture toughness is dependent on hardness. Theoretically, high hardness sample is expected to have low fracture toughness. The calculated fracture toughness for A5 and A10 is 9.61 and $8.45 \mathrm{MPa} \cdot \mathrm{m}^{1 / 2}$, respectively. With the introducing of TiC, fracture toughness decreases to 8.62 and $8.1 \mathrm{MPa} \cdot \mathrm{m}^{1 / 2}$ for $\mathrm{B} 5$ and $\mathrm{B} 10 . \mathrm{C}$ and D samples have high Vickers hardness, consequently low fracture toughness. The fracture toughness of $\mathrm{C} 5$ and $\mathrm{C} 10$ is 7.41 and $8.44 \mathrm{MPa} \cdot \mathrm{m}^{1 / 2}$, respectively. Fracture toughness increases with the continual increasing of $\mathrm{TiC}$ content and approaches to 8.2 and $8.67 \mathrm{MPa} \cdot \mathrm{m}^{1 / 2}$ for E5 and E10. There is an exception for D10 sample with a relatively low fracture toughness of $8.11 \mathrm{MPa} \cdot \mathrm{m}^{1 / 2}$ comparing with $8.44 \mathrm{MPa} \cdot \mathrm{m}^{1 / 2}$ for $\mathrm{C} 10$ sample.

Hardness and fracture toughness are the two most important properties of cermet for the structural application. It is necessary to obtain a sample with the combination of high hardness and fracture toughness. Fig. 11 
illustrates a comparison of present properties (red ones) with previous results (black ones). Previous results are taken from following references[4-6, 12, 15, 40]. Three groups samples, A, C, and E, which represent $\mathrm{TiB}_{2}-\mathrm{Ni}, \mathrm{TiC}_{-} \mathrm{TiB}_{2}$ $\mathrm{Ni}$, and $\mathrm{TiC}-\mathrm{Ni}$, are included. Red circles, red cubes, and red cross stands for $\mathrm{TiB}_{2}-\mathrm{Ni}, \mathrm{TiB}_{2}-\mathrm{TiC}-\mathrm{Ni}$, and $\mathrm{TiC}-\mathrm{Ni}$, respectively. One thing need concern is that previous reports have different loads for Vickers hardness examination and fracture toughness determination techniques. This may influence the comparison, but the graph looks reasonable after add sufficient data points. Previous results indicate that: (1) $\mathrm{TiB}_{2}-\mathrm{Fe}-\mathrm{Ni}-\mathrm{Cr}$ (results of reference 4 ) has a better combination of hardness and toughness than conventional carbide cermet (both TiC and WC based, results of references 4 and 12) at low toughness range (lower than $\sim 14 \mathrm{MPa} \cdot \mathrm{m}^{1 / 2}$ ); (2) since the metallic binder content of $\mathrm{TiB}_{2}-\mathrm{Ti}(\mathrm{C}, \mathrm{N})-(\mathrm{Ni}, \mathrm{Mo})$ composite (results of references $\left.5,6,15,40\right)$ from previous research is relative low (3 to 10 wt $\%$ ), with the hardness higher than $20 \mathrm{GPa}$, composite appears to have slightly better properties. Present $\mathrm{TiB}_{2}-\mathrm{Ni}$ and TiC-Ni cermets have similar properties comparing with literature results. $\mathrm{TiB}_{2}$ - $\mathrm{TiC}-\mathrm{Ni}$ composites show significantly better properties than that of previous $\mathrm{TiB}_{2}-\mathrm{Ti}(\mathrm{C}, \mathrm{N})-(\mathrm{Ni}, \mathrm{Mo})$ based materials; a higher toughness at similar Vickers hardness. The appearance of the high hardness is discussed before, and it is necessary to understand the toughening mechanism.

Crack propagation paths of selected sintered $\mathrm{TiB}_{2}$-TiC-Ni composites are presented in Fig. 12. Intergranular fracture dominates the fracture mold at $\mathrm{TiB}_{2} / \mathrm{TiC}$ grain boundaries. Crack deflection can be observed at where intergranular fracture happens. Transgranular cracks present mainly at some exaggerated grown TiC grains (blue arrows). Crack bridging can also be observed at some fine and coarse grains interfaces (red arrows). It is well known that the metallic phase in cermet supplies plastics deformation and the crack bridging-induced toughening. Therefore, sample with a high Ni content has a high fracture toughness correspondingly, as illustrated in Fig. 10. Also, considering the different thermal expansion coefficient (CTE) of $\mathrm{TiC}$ and $\mathrm{TiB}_{2}$ and the appearance of $\mathrm{TiB}_{2} / \mathrm{TiC}$ interfaces, stress field toughening mechanism is proposed. Wen et al studied the toughening mechanism of $\mathrm{TiB}_{2}$ - $\mathrm{TiC}$ composite obtained from reaction processing method[38]. $\mathrm{TiB}_{2}$ has anisotropic CTE with $\alpha_{a}=7.19 \times$ $10^{-6} \mathrm{~K}^{-1}$ and $\alpha_{c}=9.77 \times 10^{-6} \mathrm{~K}^{-1}$, while TiC is isotropic with $\alpha_{a}=7.2 \times 10^{-6} \mathrm{~K}^{-1}[1,16] . \mathrm{TiB}_{2}$ has higher CTE along c-axis, and similar CTE along a-axis comparing with TiC. This leads to a weak interfacial bonding at a-axis interface, and a large shear stress at c-axis interface, as indicated in Fig. 8. Interfacial stress prompts cracks propagate along the interfaces (debonding of the interfaces, as shown in Fig. 12). The formation of a debonded interface spreads the strain displacement imposed on the bridging $\mathrm{TiB}_{2}$ grains, which generates a larger crack 
opening displacement per unit of stress[41]. The increased crack opening displacement with distance behind the crack tip significantly enhances the fracture toughness. D samples do not show remarkable better properties, as blue cubes illustrated in Fig. 11. This is likely because of the polycrystalline growth of TiC grains as discussed in 3.4. Zou et al report that exaggerated grain growth of $\mathrm{TiC}$ deteriorates the fracture toughness, which can explain the relative "low" fracture toughness of D samples[15]. This is also demonstrated by the transgranular fracture of TiC grains.

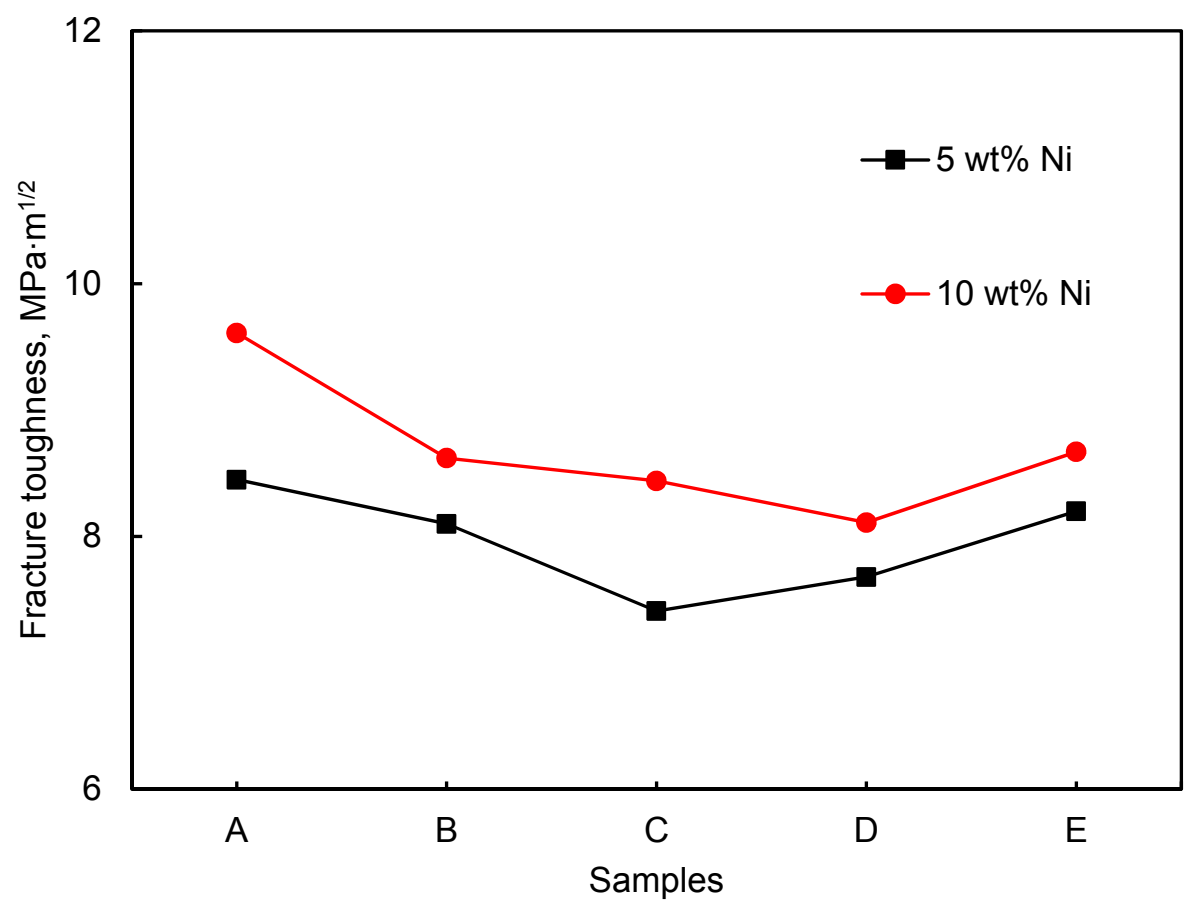

Fig. 10 Fracture toughness of samples sintered at $1550^{\circ} \mathrm{C}$ for one hour over $\mathrm{TiB}_{2} / \mathrm{TiC}$ composition and $\mathrm{Ni}$ content 


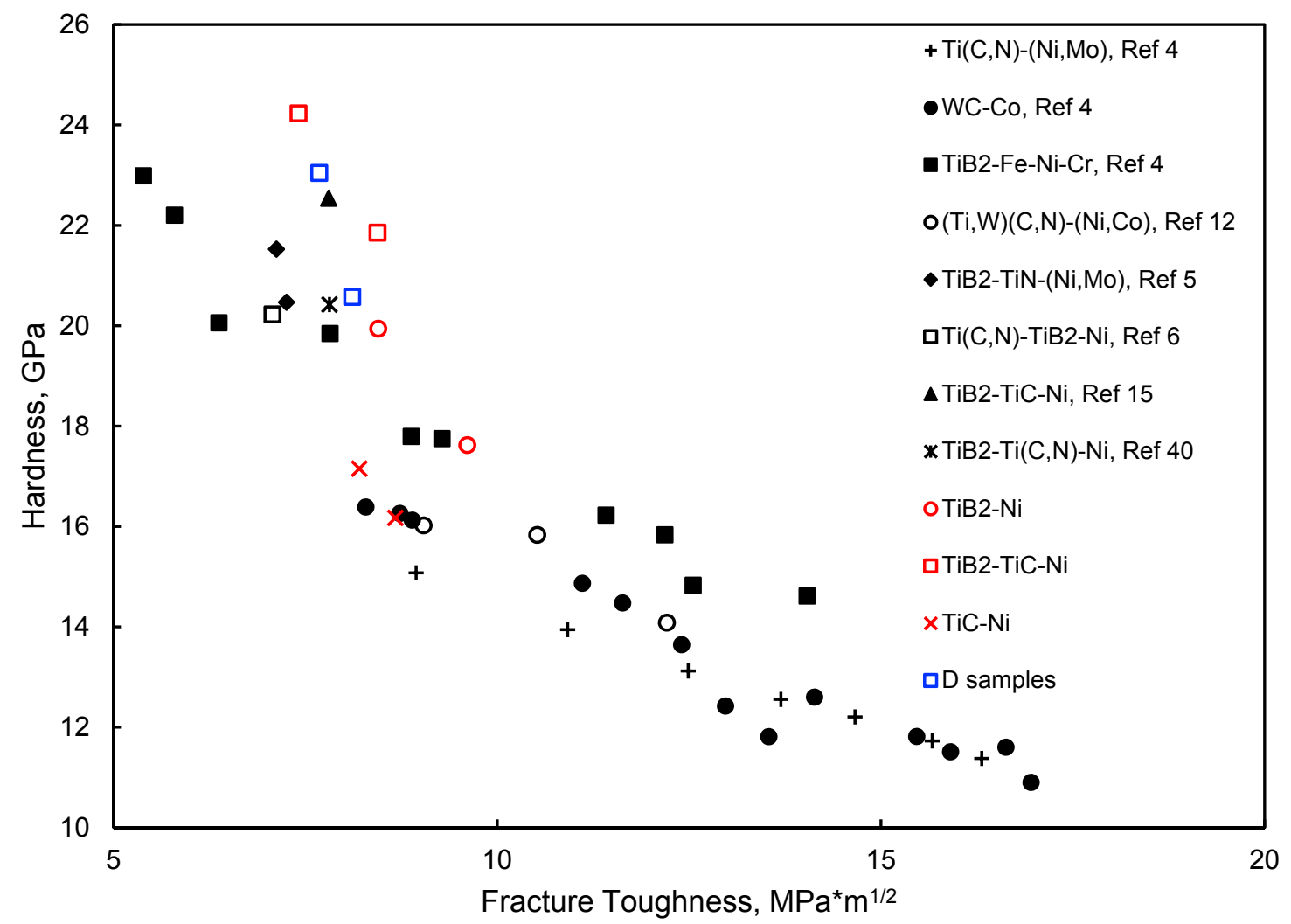

Fig. 11 A comparison of present results with literature results. Black ones are literature reported results. Red circles, red cubes, and red cross are A, C, and E samples respectively. Blue cubes are D samples. 


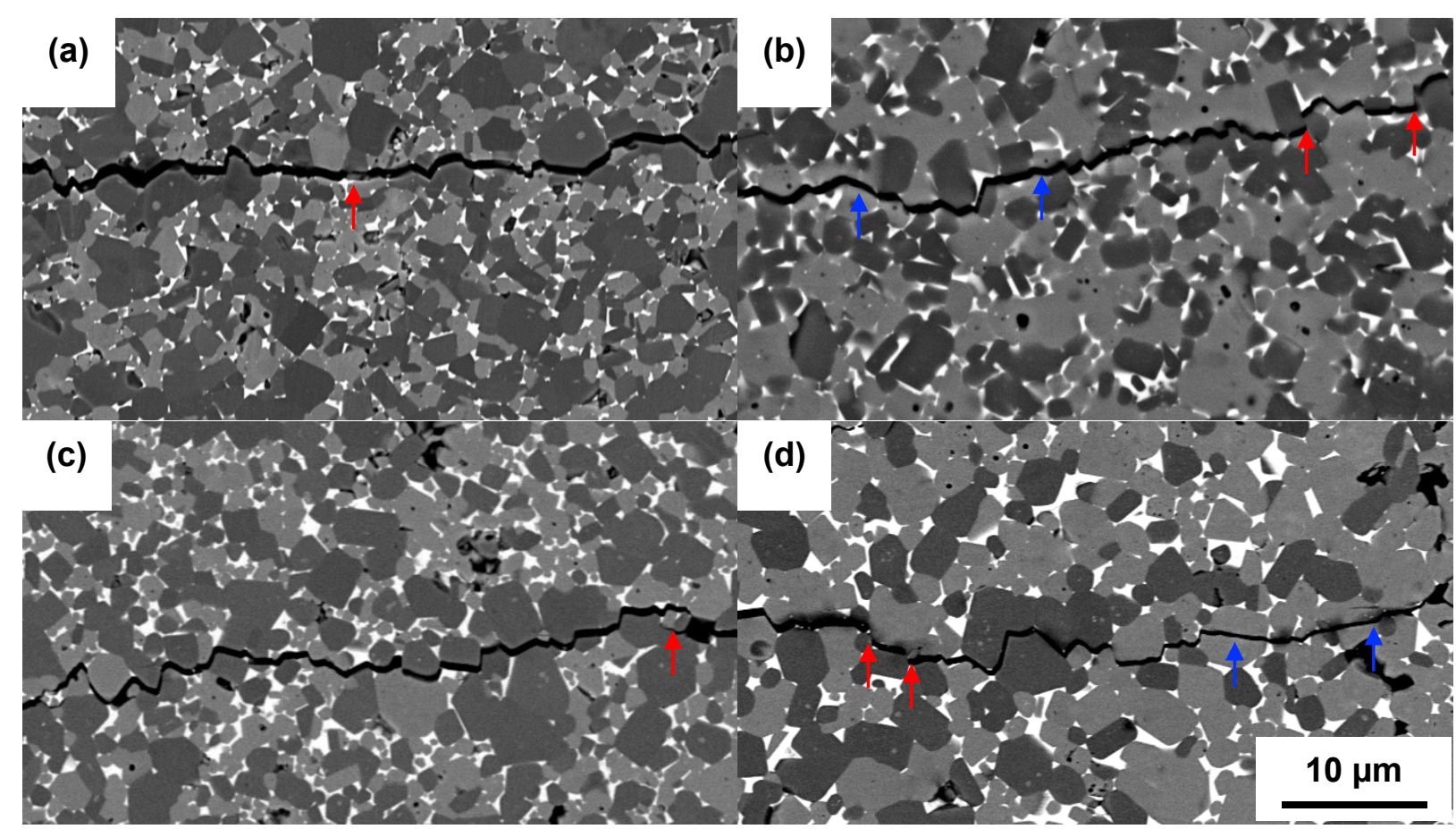

Fig. 12 Crack propagation paths of selected sintered $\mathrm{TiB}_{2}-\mathrm{TiC}-\mathrm{Ni}$ composites, red and blue arrows illustrate grain bridging and transgranular crack propagation, respectively. (a) C5, (b) D5, (c) C10, (d) D10

\section{Conclusion}

In this present work, $\mathrm{TiB}_{2}-\mathrm{TiC}-\mathrm{Ni}$ composites were fabricated with improved mechanical properties for structural applications. Sintering behavior, phases compositions, microstructures, and mechanical properties were studied. By utilizing high quality powders of $\mathrm{TiB}_{2} / \mathrm{TiC}$, a sintering temperature of $1550^{\circ} \mathrm{C}$ without applied external pressure can have relative density of $99 \%$ theoretical density. The introducing of a secondary TiC phase greatly inhibits the grain growth and therefore, the resulting composites have fine microstructures with grain size of $\sim 1.5$ to $2.8 \mu \mathrm{m}$. Plate like $\mathrm{TiB}_{2}$ grains also form owing to the anisotropic growth rate along a and c-axis planes of $\mathrm{TiB}_{2}$. Due to the fine microstructures, the composites have outstanding mechanical properties with a combination of hardness and fracture toughness as $24.23 \mathrm{GPa}, 7.41 \mathrm{MPa} \cdot \mathrm{m}^{1 / 2}$, and $21.85 \mathrm{GPa}, 8.44 \mathrm{MPa} \cdot \mathrm{m}^{1 / 2}$. The toughening mechanisms include $\mathrm{Ni}$ binder phase plastics deformation and crack bridging, and debonding of $\mathrm{TiB}_{2}$ - $\mathrm{TiC}_{\mathrm{interface}}$ caused by stress filed. It was also reported that the high content of $\mathrm{TiC}$ deteriorated the fracture toughness because of exaggerated grain growth of TiC.

\section{Acknowledgements}


Partial financial supported by a grant (DE-FE0008864) from U.S. Department of Energy was gratefully acknowledged. The first author was also supported by China Scholar Council, Project of Study Aboard (File number 201206880014).

\section{Reference:}

[1] B. Basu, G.B. Raju, A.K. Suri, Processing and properties of monolithic $\mathrm{TiB}_{2}$ based materials, International Materials Reviews 51(6) (2006) 352-374.

[2] D. Vallauri, I.C. Atías Adrián, A. Chrysanthou, TiC-TiB 2 composites: A review of phase relationships, processing and properties, Journal of the European Ceramic Society 28(8) (2008) 1697-1713.

[3] R. González, M.G. Barandika, D. Oña, J.M. Sánchez, A. Villellas, A. Valea, F. Castro, New binder phases for the consolidation of $\mathrm{TiB}_{2}$ hardmetals, Materials Science and Engineering: A 216(1-2) (1996) 185-192.

[4] R. Telle, L.S. Sigl, K. Takagi, Boride-Based Hard Materials, Handbook of Ceramic Hard Materials, Wiley-VCH Verlag GmbH 2000, pp. 802-945.

[5] M. Gu, C. Huang, B. Zou, B. Liu, Effect of (Ni, Mo) and TiN on the microstructure and mechanical properties of $\mathrm{TiB}_{2}$ ceramic tool materials, Materials Science and Engineering: A 433(1-2) (2006) 39-44.

[6] L. Wang, H. Liu, C. Huang, B. Zou, X. Liu, Effects of sintering processes on mechanical properties and microstructure of $\mathrm{Ti}(\mathrm{C}, \mathrm{N})-\mathrm{TiB}_{2}-\mathrm{Ni}$ composite ceramic cutting tool material, Ceramics International 40(10) (2014) 16513-16519.

[7] B. Zou, C. Huang, J. Song, Z. Liu, L. Liu, Y. Zhao, Mechanical properties and microstructure of $\mathrm{TiB}_{2}-\mathrm{TiC}$ composite ceramic cutting tool material, International Journal of Refractory Metals and Hard Materials 35 (2012) 19.

[8] R. Koc, C. Meng, G.A. Swift, Sintering properties of submicron TiC powders from carbon coated titania precursor, Journal of Materials Science 35(12) (2000) 3131-3141.

[9] S. Cardinal, A. Malchère, V. Garnier, G. Fantozzi, Microstructure and mechanical properties of TiC-TiN based cermets for tools application, International Journal of Refractory Metals and Hard Materials 27(3) (2009) 521-527. [10] S. Park, S. Kang, Toughened ultra-fine (Ti,W)(CN)-Ni cermets, Scripta Materialia 52(2) (2005) 129-133. [11] S.-Y. Ahn, S. Kang, Formation of Core/Rim Structures in Ti(C,N)-WC-Ni Cermets via a Dissolution and Precipitation Process, Journal of the American Ceramic Society 83(6) (2000) 1489-1494. 
[12] C. Park, S. Nam, S. Kang, Enhanced toughness of titanium carbonitride-based cermets by addition of (Ti,W)C carbides, Materials Science and Engineering: A 649 (2016) 400-406.

[13] Z. Fu, K. Mondal, R. Koc, Sintering, mechanical, electrical and oxidation properties of ceramic intermetallic $\mathrm{TiC}-\mathrm{Ti}_{3} \mathrm{Al}$ composites obtained from nano-TiC particles, Ceramics International 42(8) (2016) 9995-10005.

[14] C.C. Onuoha, G.J. Kipouros, Z.N. Farhat, K.P. Plucknett, The reciprocating wear behaviour of TiC-304L stainless steel composites prepared by melt infiltration, Wear 303(1-2) (2013) 321-333.

[15] B. Zou, C. Huang, J. Song, Z. Liu, L. Liu, Y. Zhao, Effects of sintering processes on mechanical properties and microstructure of $\mathrm{TiB}_{2}-\mathrm{TiC}+8 \mathrm{wt} \%$ nano-Ni composite ceramic cutting tool material, Materials Science and Engineering: A 540 (2012) 235-244.

[16] M.K. Ferber, P.F. Becher, C.B. Finch, Effect of Microstructure on the Properties of $\mathrm{TiB}_{2}$ Ceramics, Journal of the American Ceramic Society 66(1) (1983) C-2-C-3.

[17] M.A. Einarsrud, E. Hagen, G. Pettersen, T. Grande, Pressureless sintering of titanium diboride with nickel, nickel boride, and iron additives, Journal of the American Ceramic Society 80(12) (1997) 3013-3020.

[18] S.H. Kang, D.J. Kim, E.S. Kang, S.S. Baek, Pressureless Sintering and Properties of Titanium Diboride Ceramics Containing Chromium and Iron, Journal of the American Ceramic Society 84(4) (2001) 893-895.

[19] A.A. Ogwu, T.J. Davies, The densification and mechanical properties of a $\mathrm{TiC}$ and $\mathrm{TiB}_{2}$ hardmetal sintered with a reactive alloy binder, physica status solidi (a) 153(1) (1996) 101-116.

[20] J. Song, C. Huang, M. Lv, B. Zou, S. Wang, J. Wang, J. An, Effects of TiC content and melt phase on microstructure and mechanical properties of ternary $\mathrm{TiB}_{2}$-based ceramic cutting tool materials, Materials Science and Engineering: A 605 (2014) 137-143.

[21] J. Song, C. Huang, B. Zou, H. Liu, L. Liu, J. Wang, Effects of sintering additives on microstructure and mechanical properties of $\mathrm{TiB}_{2}-\mathrm{WC}$ ceramic-metal composite tool materials, International Journal of Refractory Metals and Hard Materials 30(1) (2012) 91-95.

[22] J. Song, C. Huang, B. Zou, H. Liu, J. Wang, Microstructure and mechanical properties of $\mathrm{TiB}_{2}-\mathrm{TiC}-\mathrm{WC}$ composite ceramic tool materials, Materials \& Design 36 (2012) 69-74.

[23] R. Koc, G. Glatzmaier, J. Sibold, $\beta$-SiC production by reacting silica gel with hydrocarbon gas, Journal of Materials Science 36(4) (2001) 995-999. 
[24] Z. Fu, R. Koc, Synthesis of $\mathrm{TiC}-\mathrm{TiB}_{2}$ composite powders from carbon coated $\mathrm{TiO}_{2}$ precursors, Ceramics International 42(10) (2016) 12231-12238.

[25] W.-M. Guo, G.-J. Zhang, Y. You, S.-H. Wu, H.-T. Lin, M.A. Einarsrud, TiB 2 Powders Synthesis by

Borothermal Reduction in $\mathrm{TiO}_{2}$ Under Vacuum, Journal of the American Ceramic Society 97(5) (2014) 1359-1362.

[26] R. Koc, G.C. Glatzmaier, Process for synthesizing titanium carbide, titanium nitride and titanium carbonitride, U.S. Patent No. 5,417,952, 1995.

[27] R. Koc, J.R. Mawdsley, J.D. Carter, Synthesis of metal borides, U.S. Patent No. 9,073,758, 2015.

[28] R. Koc, J.S. Folmer, Carbothermal synthesis of titanium carbide using ultrafine titania powders, Journal of Materials Science 32(12) (1997) 3101-3111.

[29] G.R. Anstis, P. Chantikul, B.R. Lawn, D.B. Marshall, A Critical Evaluation of Indentation Techniques for Measuring Fracture Toughness: I, Direct Crack Measurements, Journal of the American Ceramic Society 64(9) (1981) 533-538.

[30] D.K. Shetty, I.G. Wright, P.N. Mincer, A.H. Clauer, Indentation fracture of WC-Co cermets, Journal of Materials Science 20(5) (1985) 1873-1882.

[31] D. Ağaoğulları, H. Gökçe, İ. Duman, M.L. Öveçoğlu, Influences of metallic Co and mechanical alloying on the microstructural and mechanical properties of $\mathrm{TiB}_{2}$ ceramics prepared via pressureless sintering, Journal of the European Ceramic Society 32(9) (2012) 1949-1956.

[32] R.M. German, Liquid phase sintering, Plenum Press, New York and London, 1985.

[33] R.M. German, P. Suri, S.J. Park, Review: liquid phase sintering, Journal of Materials Science 44(1) (2009) 139.

[34] R. Asthana, S. Mileiko, N. Sobczak, Wettability and interface considerations in advanced heat-resistant Ni-base composites, Bulletin of the Polish Academy of Sciences Technical Sciences 54(2) (2006).

[35] S. Zaima, Y. Shibata, H. Adachi, C. Oshima, S. Otani, M. Aono, Y. Ishizawa, Atomic chemical composition and reactivity of the TiC(111) surface, Surface Science 157(2) (1985) 380-392.

[36] W. Liu, X. Liu, W.T. Zheng, Q. Jiang, Surface energies of several ceramics with NaCl structure, Surface Science 600(2) (2006) 257-264.

[37] S. Baik, P.F. Becher, Effect of Oxygen Contamination on Densification of $\mathrm{TiB}_{2}$, Journal of the American Ceramic Society 70(8) (1987) 527-530. 
[38] G. Wen, S.B. Li, B.S. Zhang, Z.X. Guo, Reaction synthesis of $\mathrm{TiB}_{2}-\mathrm{TiC}$ composites with enhanced toughness, Acta Materialia 49(8) (2001) 1463-1470.

[39] G. Grathwohl, R. Warren, The effect of cobalt content on the microstructure of liquid-phase sintered TaC-Co alloys, Materials Science and Engineering 14(1) (1974) 55-65.

[40] H. Liu, Q. Shi, C. Huang, B. Zou, L. Xu, J. Wang, In-situ fabricated $\mathrm{TiB}_{2}$ particle-whisker synergistically toughened Ti(C, N)-based ceramic cutting tool material, Chinese Journal of Mechanical Engineering 28(2) (2015) $338-342$.

[41] P.F. Becher, Microstructural Design of Toughened Ceramics, Journal of the American Ceramic Society 74(2) (1991) 255-269. 